\title{
Effects of dietary lycopene on the protection against oxidation of muscle and hepatic tissue in finishing pigs
}

\author{
Marcelise Regina Fachinello ${ }^{1, *}$, Eliane Gasparino ${ }^{1}$, Alessandra Nardina Triccia Rigo Monteiro ${ }^{2}$, \\ Cleiton Pagliari Sangali ${ }^{3}$, André Vinicius Sturzenegger Partyka', and Paulo Cesar Pozza'
}

\footnotetext{
* Corresponding Author: Marcelise Regina Fachinello Tel: +55-44-3011-8943, Fax: +55-44-3011-4919,

E-mail: lise_faqui@hotmail.com

${ }^{1}$ Department of Animal Science, State University of Maringa, Maringá, Paraná, 87020-900, Brazil ${ }^{2}$ Institut National de la Recherche Agronomique,

Agrocampus Ouest, Saint-Gilles, 35590, France

${ }^{3}$ Department of Agronomy, Integrated University

Center, Campo Mourão, Paraná, 87300-970, Brazil

ORCID

Marcelise Regina Fachinello

https://orcid.org/0000-0001-6396-4446

Eliane Gasparino

https://orcid.org/0000-0003-3065-5908

Alessandra Nardina Triccia Rigo Monteiro

https://orcid.org/0000-0003-1914-1885

Cleiton Pagliari Sangali

https://orcid.org/0000-0001-7799-3731

André Vinicius Sturzenegger Partyka

https://orcid.org/0000-0003-3423-7201

Paulo Cesar Pozza

https://orcid.org/0000-0001-8453-7371
}

Submitted Feb 16, 2019; Revised Apr 28, 2019; Accepted Jul 31, 2019
Objective: The objective of this study was to evaluate the effect of different levels of lycopene supplementation on the carcass traits, meat quality, concentration of lipid oxidation products and antioxidant potential in the meat and liver of finishing barrows and gilts.

Methods: A total of 40 barrows and 40 gilts were allotted in a completely randomized block design, arranged in a $2 \times 5$ factorial scheme, consisting of two sexes (barrows and gilts) and five dietary levels of lycopene $(0,12.5,25.0,37.5$, and $50.0 \mathrm{mg} / \mathrm{kg})$. In addition, four storage times $(0,24,48$, and $72 \mathrm{~h})$, at $4^{\circ} \mathrm{C}$, were added to the model to evaluate the longissimus lumborum muscle.

Results: An interaction $(\mathrm{p}=0.010)$ was observed between storage periods and dietary lycopene levels. The unfolding of the interaction (lycopenexperiod) showed a decreasing concentration of malondialdehyde concentration as the dietary lycopene increased, at all storage periods. No interactions ( $\mathrm{p}>0.050$ ) were observed for the 2,2 diphenyl 1 picrylhydrazyl (DPPH) in the pork. However, the percentage of DPPH radical inhibition reduced $(\mathrm{p}=0.001)$ up to $72 \mathrm{~h}$. Additionally, there was a linear increase $(\mathrm{p}=0.001)$ in the capture of DPPH radicals by antioxidants, as the dietary lycopene increased. No interactions were observed $(p>0.05)$ between the evaluated factors in liver. However, lipid oxidation was reduced by supplementing lycopene in pig diets. The capture of the DPPH radical, resulted increase in the antioxidant power exerted by lycopene in the liver $(\mathrm{p}=0.001)$. The concentrations of the thiobarbituric acid reactive substances and DPPH in the liver were affected by sex $(\mathrm{p}=0.001)$.

Conclusion: Dietary supplementation of lycopene reduced the water loss during thawing and was effective in protecting against oxidation of the longissimus lumborum muscle and liver until 72 hours of storage, and the best results were obtained by supplementing with $50.0 \mathrm{mg}$ of lycopene $/ \mathrm{kg}$ of diet.

Keywords: 2,2 Diphenyl 1 Picrylhydrazyl (DPPH); Liver; Meat; Oxidation; Pig; Thiobarbituric Acid Reactive Substances (TBARS)

\section{INTRODUCTION}

Meat has high amounts of proteins and lipids and is highly susceptible to oxidation. The oxidation processes in meat begins even before the slaughter and intensifies after slaughter and processing and storage of the meat [1]. The lipid oxidation process is one of the main factors related to meat deterioration, affecting nutritional and sensorial characteristics due to the formation of free radicals and unpleasant odors [2]. Pork is highly susceptible to these oxidative changes due to the high content of polyunsaturated fatty acids [3].

Research points to the possibility of attenuating the undesirable chemical substances in meat products through intervention with antioxidants, either through feed supplementation or by directly adding the substances to the processed meat [4]. The use of antioxidants is 
an effective way to minimize the development of oxidative rancidity, extending the shelf life and nutritional quality of the meat [5].

Lycopene belongs to the carotenoid family and is known to be a powerful antioxidant that protects cells against damage caused by reactive oxygen species because it is highly able to capture singlet oxygen molecules compared with other carotenoids [6]. In addition, lycopene helps to prevent lipid peroxidation by eliminating the initiating radicals [7]. Some studies have already shown improvements in pork quality of pigs fed diets with lycopene. Finishing pigs receiving $20 \mathrm{mg}$ lycopene $/ \mathrm{kg}$ of diet showed lower malondialdehyde (MDA) concentrations in fresh belly meat [8]. The inclusion of tomato processing by-products in pig diets during a seven weeks period improved the pork softness [9] and the inclusion of $5.0 \%$ of this byproduct in the diet increased the oxidative stability of pork, improving its nutritional quality [10]. Due to these antioxidant properties, lycopene supplementation in pig diets could improve the oxidative status of the animal and consequently the pork quality by delaying oxidative processes and improving antioxidant capacity. In the same way, the scientific literature about the effects of dietary supplementation of lycopene extract on the carcass traits and pork quality is lacking. Thus, the objective of this study was to evaluate the effect of dietary levels of lycopene on the carcass traits, meat quality, concentration of lipid oxidation products and antioxidant potential in the meat and liver of finishing barrows and gilts.

\section{MATERIALS AND METHODS}

The experiment was carried out in the swine farm of the State University of Maringá, located in Paraná State $\left(23^{\circ} 21^{\prime} \mathrm{S}, 52^{\circ}\right.$ $04^{\prime} \mathrm{W}$ and altitude of $564 \mathrm{~m}$ ), from January 2016 to May 2016. All experimental procedures were previously approved by the Animal Use and Ethics Committee (protocol n ${ }^{\circ}$ 6570200815).

\section{Animals, diet and experimental design}

Eighty pigs were used, 40 barrows and 40 gilts (Piétrain $\times$ Landrace $\times$ Large White), with an average initial body weight of $75.04 \pm 1.6 \mathrm{~kg}$ and final body weight of $100.45 \pm 3.69 \mathrm{~kg}$. The pigs were housed in conventional facilities divided into two wings, each consisting of 20 pens $\left(3 \mathrm{~m}^{2}\right)$ separated by a central corridor. Each pen had a nipple-type drinker and a semiautomatic feeder, providing ad libitum access to feed and water throughout the experimental period. The minimum and maximum temperatures inside the facilities were $19.62^{\circ} \mathrm{C} \pm 2.54^{\circ} \mathrm{C}$ and $32.11^{\circ} \mathrm{C} \pm 3.2^{\circ} \mathrm{C}$, respectively, which were measured by using a data logger (Hobo U10, Bourne, MA, USA) installed in the center of the facilities; data were collected every $30 \mathrm{~min}$ during the experimental period.

The animals were allotted in a completely randomized block design, arranged in a $2 \times 5$ factorial scheme, with eight replicates per treatment and one animal per experimental unit, and all this information was used to determine each studied parameter. Blocks were set over the time when the pigs, necessary to set at least one block, had attained approximately $75,0 \mathrm{~kg}$ of live weight. Blocks and their interactions with other sources of variation were also considered in the statistical model. Treatments consisted of two sexes (barrows and gilts) and five dietary lycopene levels $(0,12.5,25.0,37.5$, and $50.0 \mathrm{mg}$ of lycopene $/ \mathrm{kg}$ of diet.). In addition, four storage times (0, 24, 48 , and $72 \mathrm{~h}$ ), at $4^{\circ} \mathrm{C}$, were used to evaluate the thiobarbituric acid reactive substances (TBARS) and the 2,2-diphenyl-1-picrylhydrazyl radical (DPPH) of the longissimus lumborum (LL) muscle, providing a $2 \times 5 \times 4$ factorial scheme for these last parameters.

Table 1. Ingredients, chemical and energetic composition of basal diet

\begin{tabular}{|c|c|c|}
\hline Items & Barrows & Gilts \\
\hline \multicolumn{3}{|l|}{ Ingredients (\%) } \\
\hline Corn & 87.14 & 83.89 \\
\hline Soybean meal 45\% & 9.61 & 12.47 \\
\hline Soybean oil & 0.740 & 0.950 \\
\hline Dicalcium phosphate & 0.785 & 0.973 \\
\hline Limestone & 0.553 & 0.521 \\
\hline Salt & 0.203 & 0.203 \\
\hline L-lysine $\mathrm{HCl} 78.4 \%$ & 0.373 & 0.390 \\
\hline L-threonine $98.5 \%$ & 0.068 & 0.072 \\
\hline DL-methionine 99\% & 0.036 & 0.053 \\
\hline L-tryptophan 98\% & 0.022 & 0.017 \\
\hline Growth promoter ${ }^{1)}$ & 0.015 & 0.015 \\
\hline Vitamin and mineral supplement ${ }^{2)}$ & 0.400 & 0.400 \\
\hline Lycopene extract ${ }^{3)}$ & 0.000 & 0.000 \\
\hline (nert $^{4)}$ & 0.050 & 0.050 \\
\hline Total & 100.00 & 100.00 \\
\hline \multicolumn{3}{|l|}{ Composition } \\
\hline Metabolizable energy (Mcal/kg) & 3.30 & 3.30 \\
\hline Nitrogen $(\%)$ & 1.86 & 2.03 \\
\hline Total calcium (\%) & 0.45 & 0.49 \\
\hline Available phosphorus (\%) & 0.23 & 0.26 \\
\hline Potassium (\%) & 0.42 & 0.47 \\
\hline Sodium (\%) & 0.10 & 0.10 \\
\hline Chlorine (\%) & 0.18 & 0.18 \\
\hline SID lysine (\%) & 0.690 & 0.770 \\
\hline SID met+cis (\%) & 0.400 & 0.440 \\
\hline SID threonine (\%) & 0.440 & 0.480 \\
\hline SID tryptophan (\%) & 0.120 & 0.130 \\
\hline \multicolumn{3}{|c|}{$\begin{array}{l}\text { SID, standardized ileal digestibility. } \\
\text { 1) Enramycin } 0.015 \% \text {. } \\
\text { 2) Content } \mathrm{kg}^{-1} \text { diet; vit. A, } 30,000 \mathrm{Ul} \text {; vit. } \mathrm{D}_{3}, 5,000 \mathrm{Ul} \text {; vit. E, } 120 \mathrm{Ul} \text {; vit. K, } 5 \mathrm{mg} \text {; } \\
\text { vit. } \mathrm{B}_{12}, 120 \mathrm{mcg} \text {; niacin, } 150 \mathrm{mg} \text {; calcium pantothenate, } 75 \mathrm{mg} \text {; folic acid, } 8 \mathrm{mg} \text {; } \\
\text { choline chloride, } 0.48 \mathrm{~g} \text {; iron, } 350 \mathrm{mg} \text {; copper, } 15 \mathrm{mg} \text {; manganese, } 250 \mathrm{mg} \text {; Zinc, } \\
0.75 \mathrm{~g} \text {; iodine, } 10 \mathrm{mg} \text {; selenium, } 3 \mathrm{mg} \text {. } \\
{ }^{3)} \text { Commercial product, containing } 10 \% \text { of a nature-identical, stable formulation of } \\
\text { lycopene (Redivivo } 10 \% \text { ) with characteristic flavor and odor, replacing the inert of } \\
\text { the basal diets. } \\
\text { 4) Fine clean sand. }\end{array}$} \\
\hline
\end{tabular}


The experimental diets (Table 1) were formulated based on corn, soybean meal, minerals, vitamins, and additives, to meet the nutritional requirements proposed by NRC (National Research Council), for each sex. A commercial product containing $10 \%$ of a nature-identical, stable formulation of lycopene (Redivivo 10\%) with characteristic flavor and odor, was added to the diets, replacing $0,125,250,375$, and $500 \mathrm{mg}$ of inert material (fine clean sand), corresponding to the levels of 0 , $12.5,25.0,37.5$, and $50.0 \mathrm{mg}$ of lycopene $/ \mathrm{kg}$ of diet. The daily lycopene intake was calculated based on the daily feed intake and the percentage of lycopene included in each diet.

Carcass traits, pork quality and relative organ weight

At the end of the feeding trial, the pigs were fasted for $24 \mathrm{~h}$, weighed to obtain the live weight and then slaughtered in the abattoir of the Maringá State University. The pigs were subjected to electrical stunning (200 W) and then killed by exsanguination, shaved and gutted.

Carcasses were longitudinally middle-divided, weighed and chilled $\left(2^{\circ} \mathrm{C} \pm 1^{\circ} \mathrm{C}\right.$ for 24 hours) to evaluate the hot carcass weight ( $\mathrm{HCW})$, cold carcass weight (CCW), hot carcass yield (HCY), cold carcass yield (CCY), carcass weight loss after cooling, ham yield, backfat thickness (BT), and depth of LL muscle (LL depth) according to the guidelines of Bridi and Silva [11].

The BT and LL depth were measured in the left half of the carcass 24 hours post-mortem using a pachymeter at the insertion of the last thoracic vertebra with the first lumbar, six centimeters from the midline of the carcass (point P2). The lean meat yield (LMY) was predicted by using the equation, as follows: $\mathrm{LMY}(\%)=60-([\mathrm{BT} \mathrm{mm} \times 0.58]+[\mathrm{LL}$ depth $\mathrm{mm} \times$ $0.10])$. The liver and kidneys were weighed, and the relative weights were expressed as a percentage of the HCW. Abdominal fat was also removed and weighed to obtain its relative weight, based on the CCW.

The meat $\mathrm{pH}$ was measured in the LL muscle with the aid of a HI 99163 digital portable $\mathrm{pH}$ meter (Hanna Instruments, Woonsocket, RI, USA) at the height of the last rib 45 minutes after slaughter (pH45) and after 24 hours of cooling (pH24), according to Bridi and Silva [11].

Three samples ( $2.5 \mathrm{~cm}$ thickness) of the LL muscle of each animal were used for the qualitative evaluations, obtained at the insertion of the last thoracic vertebra with the first lumbar, in the caudal-cranial direction, as described by Bridi and Silva [11]. The first sample was used for color evaluation, the second was used for drip loss (DL), and the third was used to determine the thawing loss (TL), cooking loss (CL) and shear force (SF) [11].

The DL was evaluated according to the procedures described by Boccard et al [12]. To obtain the TL, the frozen samples were weighed, packed in polythene bags, identified and stored in a refrigerator during 24 hours at $4^{\circ} \mathrm{C}$ to thaw, and the samples were placed in plastic trays, avoiding stacking them. After 24 hours, the samples were withdrawn from the refrigerator, lightly wiped with paper towel and weigheted again. The CL was obtained from the weight difference between the thawed sample and the sample after baking in a preheated oven at $170^{\circ} \mathrm{C}$, until reaching an internal temperature of $71^{\circ} \mathrm{C}[11]$.

Cooked muscle samples were used to determine SF. Six subsamples with a cylindrical shape $(1.27 \mathrm{~cm}$ in diameter $)$ were longitudinally drawn towards the muscle fibers. The SF was evaluated perpendicular to the orientation of the muscle fibers with the Warner-Bratzler blade adapted in the Stable Mycro Systems TA-XT2i texturometer using a pre-test speed of $5 \mathrm{~mm} / \mathrm{s}$ in the $2 \mathrm{~mm} / \mathrm{s}$ test and the $5 \mathrm{~mm} / \mathrm{s}$ post-test, as recommended for pork.

The color evaluation was performed by six Minolta lightness measurements $\left(\mathrm{L}^{*}, \mathrm{a}^{*}\right.$, and $\left.\mathrm{b}^{*}\right)$ using a portable colorimeter CR-400 Konica Minolta (settings: Illuminant D65, Ramsey, NJ, USA); $0^{\circ}$ viewing angle; and 4 auto-average). The components $\mathrm{L}^{*}$ (lightness), $\mathrm{a}^{*}$ (red-green), and $\mathrm{b}^{*}$ (yellow-blue) were expressed using the CIELAB color system.

\section{Determination of thiobarbituric acid reactive substances}

The lipid oxidation evaluation was carried out by determining the substances reactive to thiobarbituric acid. The lipid oxidation evaluation was carried out by determining the reactive substances to thiobarbituric acid. For the samples of hepatic tissue, this evaluation was performed only at hour 0 (slaughter), and for LL muscle the evaluations were performed at hour 0 (slaughter) and at the storage periods of 24,48 , and 72 hours after slaughter (i.e. storage periods of $0,24,48$, and 72 hours). Samples were collected and stored (liquid nitrogen) until analysis and, after that, were thawed at environmental temperature and monitored until reaching $4^{\circ} \mathrm{C}$, packed in plastic film and randomly distributed for cooling storage $\left(4^{\circ} \mathrm{C}\right)$ at the different periods.

These procedures were performed according to the improved methodology of Juncher et al [13].

A standard curve was fitted using 1,1,3,3-tetraethoxypropane and distilled water. The absorbance reading was performed at a wavelength of $532 \mathrm{~nm}$, and the results were expressed as $\mathrm{mg}$ of malonaldehyde/Eq. $\mathrm{kg}$ of tissue.

\section{Determination of total antioxidant activity by \\ 2,2-diphenyl-1-picrylhydrazyl radicals}

The analysis of DPPH radical is based on the capture of the DPPH radical by antioxidants, i.e., the determination of the antioxidant capacity of the sample in reducing the DPPH radical, resulting in a decrease in absorbance (Abs) at $515 \mathrm{~nm}$, according to the methodology described by Brand-Williams et al [14] and Li et al [15], with modifications, and using a 0.06 
mM DPPH solution.

The LL muscle samples were analyzed at $0,24,48$, and 72 hours after refrigeration, and the hepatic tissue samples were evaluated at hour 0 (slaughter). The collection and preparation of the samples proceeded in the same manner as previously described for the TBARS.

The effective concentration that inhibited $50 \%$ of the initial concentration of the DPPH radical was determined, with readings at $515 \mathrm{~nm}$. The results were obtained as follows:

$$
\begin{aligned}
& \% \text { Inhibition DPPH } \\
& \quad=[(\text { Abs control }- \text { Abs sample }) / \text { Abs control }] \times 100
\end{aligned}
$$

\section{Statistical analysis}

The carcass traits, meat quality, relative organ weight, liver concentrations of DPPH and TBARS were statistically evaluated considering a $2 \times 5$ factorial scheme, consisting of two sexes (male and female) and five lycopene levels (0, 12.5, 25.0, 37.5 , and $50.0 \mathrm{mg} / \mathrm{kg}$ of diet). Additionally, the DPPH and TBARS of the LL muscle were statistically evaluated considering a $2 \times 5 \times 4$ factorial scheme, consisting of two sexes (males and females), five lycopene levels $(0,12.5,25.0,37.5$, and $50.0 \mathrm{mg} / \mathrm{kg}$ of diet) and four storage times $(0,24,48$, and $72 \mathrm{~h})$.

The UNIVARIATE procedure was used to evaluate the presence of outliers. Subsequently, data were submitted to analysis of variance, and the effects of blocks, sex, lycopene levels and interactions were used in the model to evaluate the carcass traits, meat quality, relative body weight, $\mathrm{DPPH}$ and TBARS in the liver, as previously described for the $2 \times 5$ factorial scheme. Additionally, the effects of storage period (i.e., $0,24,48$, and $72 \mathrm{~h}$ ) and the interactions with the other sources of variation (i.e., sex and lycopene levels) were also used to evaluate the DPPH and TBARS of LL muscle, according to the $2 \times 5 \times 4$ factorial scheme previously described.

\section{RESULTS}

Daily lycopene intake, carcass traits, pork quality, and relative organ weights

To the variable daily lycopene intake an interaction was observed between the sex and dietary lycopene levels $(p=0.006)$ (Table 2). The unfolding of the interaction revealed an increase in lycopene intake as the dietary lycopene supplementation was increased ( $\mathrm{p}=0.001)$, adjusted to fit the equation $\hat{\mathrm{Y}}=$ $2.6342 \mathrm{x}-0.167\left(\mathrm{R}^{2}=0.99\right)$. The barrows daily lycopene intake was greater in relation to the gilts $(\mathrm{p}=0.001)$. The carcass traits and relative organ weights were not affected by dietary lycopene levels ( $p>0.05$ ), and likewise, no interactions were observed (Table 2). Differences between sexes were observed, since barrows presented a higher HCY ( $p=0.049)$, CCY ( $p=$ $0.023)$, BT $(p=0.001)$ and abdominal fat $(p=0.001)$ than gilts.

No interactions $(p>0.05)$ between the evaluated factors were observed for the qualitative characteristics of the LL muscle (Table 3). The DL and CL were not affected by lycopene levels ( $p>0.05$ ), providing a positive effect with lycopene supplementation, since the water losses of the LL muscle did not increase. In the same way, the $\mathrm{pH} 45$ and $\mathrm{pH} 24$ were also not affected ( $p>0.05$ ) by lycopene levels (Table 3$)$. The TL decreased in a linear manner $(\mathrm{p}=0.024)$ as lycopene levels increased in the diets, fitting the equation $\hat{\mathrm{Y}}=-0.0244 \mathrm{x}+6.9282\left(\mathrm{R}^{2}=0.89\right.$; residual standard deviation $[\mathrm{RSD}]=0.7710)$. The SF showed a tendency toward reduction $(\mathrm{p}=0.064)$ according to increasing dietary lycopene levels.

\begin{tabular}{|c|c|c|c|c|c|c|c|c|c|c|c|c|c|c|c|}
\hline \multirow{3}{*}{ Items } & \multirow{2}{*}{\multicolumn{5}{|c|}{$\begin{array}{c}\text { Barrows } \\
\text { Lycopene (mg/kg of diet) }\end{array}$}} & \multirow{2}{*}{\multicolumn{5}{|c|}{$\begin{array}{l}\text { Gilts } \\
\text { (mg/kg of diet) }\end{array}$}} & \multirow{3}{*}{ SEM } & \multicolumn{4}{|c|}{$p$-value } \\
\hline & & & & & & & & & & & & \multirow{2}{*}{ Sexxlycopene } & \multirow{2}{*}{ Sex } & \multicolumn{2}{|c|}{ Lycopene } \\
\hline & 0 & 12.5 & 25.0 & 37.5 & 50.0 & 0 & 12.5 & 25.0 & 37.5 & 50.0 & & & & $\operatorname{Lin}^{1)}$ & Qua $^{2)}$ \\
\hline Daily lycopene intake (mg) & 0.00 & 34.61 & 71.72 & 101.11 & 140.79 & 0.00 & 29.85 & 61.21 & 94.85 & 122.73 & 14.638 & 0.006 & 0.001 & $0.001^{3)}$ & 0.618 \\
\hline Hot carcass weight $(\mathrm{kg})$ & 78.88 & 78.80 & 81.55 & 79.85 & 81.32 & 79.98 & 79.08 & 77.64 & 81.41 & 79.98 & 0.329 & 0.279 & 0.557 & 0.160 & 0.712 \\
\hline Hot carcass yield (\%) & 82.17 & 82.75 & 83.33 & 83.16 & 83.28 & 76.99 & 76.53 & 75.04 & 78.75 & 77.33 & 0.098 & 0.524 & 0.049 & 0.375 & 0.641 \\
\hline Cold carcass weight $(\mathrm{kg})$ & 76.40 & 76.42 & 78.53 & 77.47 & 78.80 & 82.64 & 82.15 & 81.97 & 82.75 & 82.07 & 0.344 & 0.400 & 0.454 & 0.124 & 0.705 \\
\hline Cold carcass yield (\%) & 79.59 & 80.24 & 80.25 & 80.68 & 80.72 & 79.54 & 79.50 & 79.22 & 79.91 & 79.36 & 0.126 & 0.855 & 0.023 & 0.265 & 0.742 \\
\hline Carcass weight loss in cooling (\%) & 3.13 & 3.03 & 3.69 & 2.99 & 3.07 & 3.75 & 3.22 & 3.35 & 3.28 & 3.30 & 0.083 & 0.558 & 0.293 & 0.371 & 0.903 \\
\hline Ham yield (\%) & 29.27 & 29.30 & 29.09 & 29.27 & 29.63 & 30.23 & 29.84 & 29.60 & 29.21 & 30.13 & 0.126 & 0.906 & 0.117 & 0.944 & 0.155 \\
\hline Lean meat yield (\%) & 57.54 & 56.25 & 58.24 & 56.66 & 58.04 & 59.21 & 59.39 & 59.10 & 58.93 & 58.81 & 0.212 & 0.646 & 0.004 & 0.784 & 0.065 \\
\hline Backfat thickness (cm) & 1.56 & 1.80 & 1.46 & 1.65 & 1.53 & 1.24 & 1.19 & 1.22 & 1.28 & 1.24 & 0.035 & 0.767 & 0.004 & 0.627 & 0.650 \\
\hline $\mathrm{LL}$ depth $(\mathrm{cm})$ & 6.07 & 5.93 & 6.35 & 6.25 & 6.11 & 6.40 & 6.31 & 6.20 & 6.34 & 5.93 & 0.052 & 0.569 & 0.451 & 0.546 & 0.361 \\
\hline Relative weight of liver (\%) & 1.739 & 1.716 & 1.636 & 1.735 & 1.603 & 1.694 & 1.711 & 1.685 & 1.657 & 1.759 & 0.010 & 0.361 & 0.717 & 0.484 & 0.669 \\
\hline Relative weight of kidney (\%) & 0.393 & 0.400 & 0.381 & 0.383 & 0.367 & 0.393 & 0.439 & 0.366 & 0.422 & 0.401 & 0.008 & 0.713 & 0.203 & 0.519 & 0.817 \\
\hline Relative weight of abdominal fat (\%) & 1.833 & 1.739 & 1.630 & 1.872 & 1.992 & 1.312 & 1.346 & 1.401 & 1.414 & 1.525 & 0.044 & 0.524 & 0.001 & 0.055 & 0.122 \\
\hline
\end{tabular}

Table 2. Daily lycopene intake, carcass traits and relative organ weights of barrows and gilts, from 75 to $100 \mathrm{~kg}$, fed diets containing different lycopene levels

The eighty samples used.

SEM, standard error of the mean; LL depth, depth of longissimus lumborum.

1) Linear effect of lycopene levels.

2) Quadratic effect of lycopene levels.

3) $\hat{Y}=2.6342 x-0.167\left(R^{2}=0.99\right)$. 
Table 3. Qualitative characteristics of the longissimus lumborum muscle of barrows and gilts, from 75 to $100 \mathrm{~kg}$, fed diets containing different lycopene levels

\begin{tabular}{|c|c|c|c|c|c|c|c|c|c|c|c|c|c|c|c|}
\hline \multirow{3}{*}{ Items } & \multirow{2}{*}{\multicolumn{5}{|c|}{$\begin{array}{c}\text { Barrows } \\
\text { Lycopene (mg/kg of diet) }\end{array}$}} & & & Gilts & & & \multirow{3}{*}{ SEM } & \multicolumn{4}{|c|}{$p$-value } \\
\hline & & & & & & & Lycoper & $(\mathrm{mg} / \mathrm{kg}$ & $f$ diet) & & & \multirow{2}{*}{ Sexxlycopene } & \multirow{2}{*}{ Sex } & \multicolumn{2}{|c|}{ Lycopene } \\
\hline & 0 & 12.5 & 25.0 & 37.5 & 50.0 & 0 & 12.5 & 25.0 & 37.5 & 50.0 & & & & $\operatorname{Lin}^{11}$ & Qua $^{2)}$ \\
\hline pH45 & 6.34 & 6.31 & 6.36 & 6.30 & 6.30 & 6.28 & 6.20 & 6.53 & 6.41 & 6.43 & 0.031 & 0.745 & 0.627 & 0.506 & 0.689 \\
\hline pH24 & 5.75 & 5.82 & 5.71 & 5.79 & 5.76 & 5.75 & 5.72 & 5.90 & 5.73 & 5.85 & 0.012 & 0.838 & 0.595 & 0.474 & 0.838 \\
\hline Drip loss (\%) & 5.35 & 5.64 & 4.93 & 5.08 & 4.75 & 5.14 & 4.89 & 4.92 & 3.93 & 4.47 & 0.152 & 0.915 & 0.269 & 0.199 & 0.950 \\
\hline Minolta L* & 56.57 & 55.70 & 57.77 & 58.33 & 59.04 & 57.21 & 57.06 & 56.43 & 56.83 & 54.84 & 0.193 & 0.880 & 0.147 & 0.613 & 0.880 \\
\hline Minolta $a^{*}$ & 6.50 & 6.26 & 7.14 & 6.54 & 7.02 & 5.27 & 5.41 & 5.31 & 5.56 & 5.61 & 0.093 & 0.524 & 0.001 & 0.258 & 0.975 \\
\hline Minolta $b^{*}$ & 3.34 & 3.13 & 3.85 & 3.71 & 3.37 & 3.22 & 3.36 & 2.99 & 3.17 & 2.55 & 0.085 & 0.388 & 0.045 & 0.531 & 0.232 \\
\hline Thawing loss $(\%)^{3)}$ & 7.28 & 6.65 & 5.83 & 5.81 & 5.41 & 6.77 & 6.70 & 6.20 & 6.34 & 6.19 & 0.229 & 0.846 & 0.524 & 0.024 & 0.571 \\
\hline Cooking loss (\%) & 27.48 & 26.53 & 26.57 & 24.89 & 25.94 & 24.51 & 24.72 & 24.34 & 25.31 & 24.33 & 0.165 & 0.806 & 0.111 & 0.548 & 0.909 \\
\hline Shear force (N) & 30.11 & 29.91 & 29.22 & 26.87 & 25.89 & 28.15 & 28.05 & 27.65 & 27.26 & 27.36 & 0.193 & 0.655 & 0.592 & 0.064 & 0.635 \\
\hline
\end{tabular}

The eighty samples used.

SEM, standard error of the mean. RSD, residual standard deviation.

1) Linear effect of lycopene levels.

${ }^{2)}$ Quadratic effect of lycopene levels.

${ }^{3)} \hat{Y}=-0.0244 x+6.9282\left(R^{2}=0.89 ; R S D, 0.7710\right)$; the independent variable " $x$ " represents the lycopene levels in the fitted equations.

The color of the LL muscle was not affected ( $p>0.05)$ by dietary lycopene levels, but sex showed differences for $\mathrm{a}^{*}(\mathrm{p}=$ $0.001)$ and $b^{\star}(p=0.045)$, in which the barrows showed higher staining intensity for the red-green and blue-yellow components, respectively.

Total antioxidant activity by the DPPH radical and lipid oxidation by thiobarbituric acid reactive substances of the LL muscle

An interaction was observed $(\mathrm{p}=0.006)$ between the storage periods and dietary lycopene levels (Table 4). The unfolding of the interaction revealed a reduction in lipid oxidation as the dietary lycopene supplementation was increased, for all evaluated periods (Figure 1a), adjusted to fit the equations $\hat{Y}$ $=-0.0001 \mathrm{x}+0.0799\left(\mathrm{R}^{2}=0.92 ; \mathrm{RSD}=0.0016\right), \hat{\mathrm{Y}}=-0.0002 \mathrm{x}+$ $0.0994\left(R^{2}=0.85 ; R S D=0.0017\right), \hat{Y}=-0.0003 x+0.1224\left(R^{2}\right.$ $=0.97 ; \mathrm{RSD}=0.0012)$, and $\hat{\mathrm{Y}}=-0.0003 \mathrm{x}+0.1453\left(\mathrm{R}^{2}=1.00\right.$; $\mathrm{RSD}=0.0018$ ), for the storage periods of $0,24,48$, and 72 hours, respectively. When evaluating the interaction within each lycopene level, linear and quadratic equations were fitted over the evaluated periods, but the linear model explained the observed data better, according to the determination coefficients, in which an increase in lipid oxidation showed a direct correlation with the increasing storage time (Figure 1B), fitting the equations $\hat{Y}=0.0009 x+0.0793\left(R^{2}=0.91\right.$; RSD $=$ $0.0008), \hat{Y}=0.0008 x+0.0781\left(R^{2}=0.88 ; R S D=0.0029\right), \hat{Y}=$ $0.0008 \mathrm{x}+0.0757\left(\mathrm{R}^{2}=0.88 ; \mathrm{RSD}=0.0034\right), \hat{\mathrm{Y}}=0.0007 \mathrm{x}+$ $0.0769\left(R^{2}=0.89 ; R S D=0.0026\right)$, and $\hat{Y}=0.0007 x+0.0750$ $\left(\mathrm{R}^{2}=0.89 ; \mathrm{RSD}=0.0025\right)$, for the levels $0,12.5,25.0,37.5$, and $50.0 \mathrm{mg}$ of lycopene $/ \mathrm{kg}$ of diet, respectively.

No interactions between lycopene levels and sex were observed ( $p>0.05$ ) for the inhibition of the DPPH radical in the LL muscle. However, the DPPH radical was affected by the storage period and dietary lycopene levels (Table 5). The inhibition of the DPPH radical in the meat was reduced up to $72 \mathrm{~h}$, as described by the equations $\hat{\mathrm{Y}}=0.0594 \mathrm{x}+39.70\left(\mathrm{R}^{2}=\right.$ $0.97 ; \mathrm{RSD}=0.1677)$ and $\hat{\mathrm{Y}}=0.0005 \mathrm{x}^{2}-0.0956 \mathrm{x}+39.99\left(\mathrm{R}^{2}=\right.$ 1.00 ), but the derivation of the quadratic equation overestimated the storage time $(95.6 \mathrm{~h})$.

In addition, increasing dietary lycopene levels provided an increase $(\mathrm{p}=0.001)$ in the capture of DPPH radicals by antioxidants in the LL muscle, as described by the equation

Table 4. Effects of dietary levels of lycopene for barrows and gilts (75 to $100 \mathrm{~kg}$ ) on lipid oxidation (mg MDA Eq/kg) of the longissimus lumborum muscle at different storage periods

\begin{tabular}{|c|c|c|c|c|c|c|c|c|c|c|c|}
\hline \multirow{3}{*}{ Periods (h) } & \multicolumn{5}{|c|}{ Barrows } & \multicolumn{5}{|c|}{ Gilts } & \multirow{3}{*}{ SEM } \\
\hline & \multicolumn{5}{|c|}{ Lycopene (mg/kg of diet) } & \multicolumn{5}{|c|}{ Lycopene (mg/kg of diet) } & \\
\hline & 0 & 12.5 & 25.0 & 37.5 & 50.0 & 0 & 12.5 & 25.0 & 37.5 & 50.0 & \\
\hline 0 & 0.0803 & 0.0787 & 0.0775 & 0.0769 & 0.0762 & 0.0797 & 0.0804 & 0.0784 & 0.0791 & 0.0783 & 0.001 \\
\hline 24 & 0.1009 & 0.0985 & 0.0923 & 0.0936 & 0.0869 & 0.0993 & 0.0957 & 0.0917 & 0.0942 & 0.0920 & 0.002 \\
\hline 48 & 0.1237 & 0.1184 & 0.1175 & 0.1101 & 0.1073 & 0.1210 & 0.1169 & 0.1165 & 0.1108 & 0.1068 & 0.003 \\
\hline 72 & 0.1470 & 0.1431 & 0.1401 & 0.1339 & 0.1289 & 0.1431 & 0.1393 & 0.1335 & 0.1292 & 0.1270 & 0.003 \\
\hline
\end{tabular}

The eighty samples used.

MDA, malondialdehyde; SEM, standard error of the mean.

Statistical significances: lycopene, linear effect $(p=0.001)$; period, linear $(p=0.001)$ and quadratic $(p=0.001)$ effects; no effects for sex $(p=0.213)$ period $\times$ lycopene $(p$ $=0.006)$ sex $\times$ period $(p=0.099)$, sex $\times$ lycopene $(p=0.635)$, and period $\times \operatorname{sex} \times$ lycopene $(p=0.704)$. 


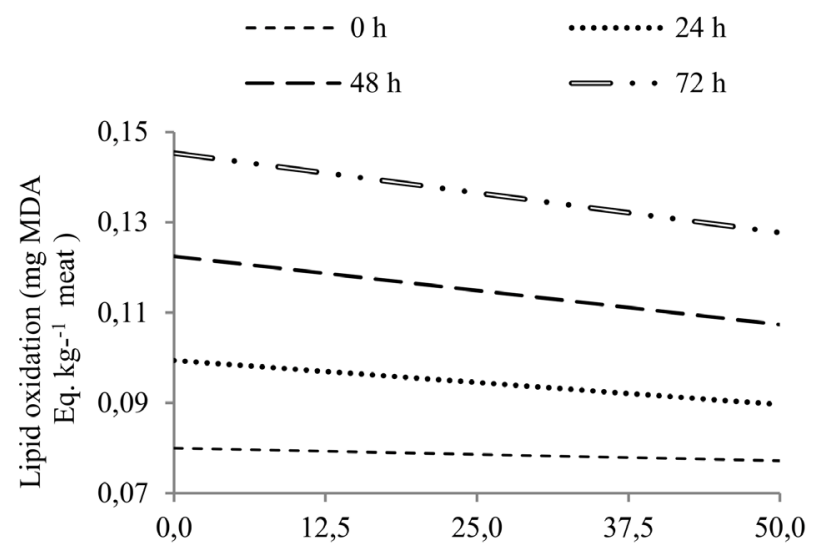

Lycopene levels $\left(\mathrm{mg} \mathrm{kg}^{-1}\right.$ of diet)

(a)
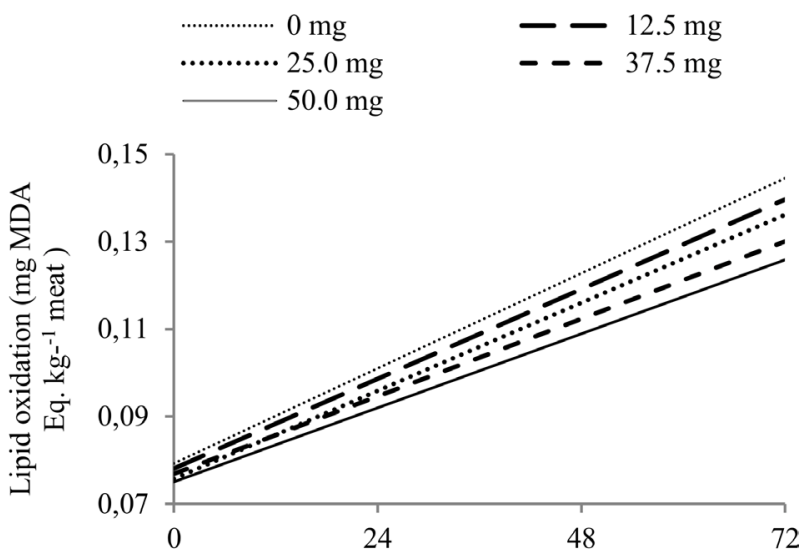

Storage period (hours)

(b)

Figure 1. Measurement of lipid oxidation in terms of thiobarbituric acid reactive substances (TBARS). (a) at different storage periods according to lycopene levels, fitting the equations $\hat{Y}=-0.0001 x+0.0799\left(R^{2}=0.92 ; R S D=0.0016\right), \hat{Y}=-0.0002 x+0.0994\left(R^{2}=0.85 ; R S D=0.0017\right), \hat{Y}=-0.0003 x+0.1224\left(R^{2}=0.97 ; R S D=0.0012\right)$, and $\hat{Y}=-0.0003 x+0.1453\left(R^{2}=1.00 ; R S D=0.0018\right)$; for $0,24,48$, and 72 hours, respectively. (b) at each lycopene level over the storage periods of the longissimus lumborum muscle, fitting the equations $\hat{Y}=0.0009 x+0.0793\left(R^{2}=0.91 ; R S D=0.0008\right), \hat{Y}=0.0008 x+0.0781\left(R^{2}=0.88 ; R S D=0.0029\right), \hat{Y}=0.0008 x+0.0757\left(R^{2}=\right.$ $0.88 ; R S D=0.0034), \hat{Y}=0.0007 x+0.0769\left(R^{2}=0.89 ; R S D=0.0026\right)$, and $\hat{Y}=0.0007 x+0.0750\left(R^{2}=0.89 ; R S D=0.0025\right) ;$ for $0 ; 12.5 ; 25.0 ; 37.5 ;$ and $50.0 \mathrm{mg}$ of lycopene/kg of diet, respectively.

Table 5. Effects of dietary levels of lycopene for barrows and gilts (75 to $100 \mathrm{~kg}$ ) on the \% of inhibition of DPPH radicals in the longissimus lumborum muscle

\begin{tabular}{|c|c|c|c|c|c|c|c|c|c|c|c|}
\hline \multirow{3}{*}{ Periods (h) } & \multicolumn{5}{|c|}{ Barrows } & \multicolumn{5}{|c|}{ Gilts } & \multirow{3}{*}{ SEM } \\
\hline & \multicolumn{5}{|c|}{ Lycopene (mg/kg of diet) } & \multicolumn{5}{|c|}{ Lycopene (mg/kg of diet) } & \\
\hline & 0 & 12.5 & 25.0 & 37.5 & 50.0 & 0 & 12.5 & 25.0 & 37.5 & 50.0 & \\
\hline 0 & 38.771 & 39.107 & 39.012 & 40.768 & 40.733 & 39.343 & 39.809 & 40.284 & 41.284 & 40.923 & 0.407 \\
\hline 24 & 36.675 & 37.764 & 38.274 & 37.451 & 38.989 & 37.227 & 37.606 & 38.219 & 38.304 & 39.311 & 0.358 \\
\hline 48 & 34.938 & 36.375 & 36.541 & 37.011 & 37.083 & 35.045 & 36.578 & 36.958 & 37.503 & 37.788 & 0.421 \\
\hline 72 & 34.349 & 35.816 & 36.181 & 36.401 & 36.549 & 34.063 & 35.177 & 35.213 & 36.532 & 36.919 & 0.438 \\
\hline
\end{tabular}

The eighty samples used.

DPPH, radical 2,2-diphenyl-1-picrylhydrazide; SEM, standard error of the mean.

Statistical significances: lycopene, linear $(p=0.001)$ and quadratic (0.362) effects; period, linear ( $p=0.001)$ and quadratic $(p=0.018)$ effects; no effects for sex $(p=0.278)$

period $\times$ lycopene $(p=0.962)$ sex $\times$ period $(p=0.587)$, sex $\times$ lycopene $(p=0.950)$, and period $\times$ sex $\times$ lycopene $(p=0.507)$.

$\hat{\mathrm{Y}}=0.04279 \mathrm{x}+36.50\left(\mathrm{R}^{2}=0.96 ; \mathrm{RSD}=0.3351\right)$.

Total antioxidant activity by the DPPH radical and lipid oxidation by the thiobarbituric acid reactive

\section{substances of the liver}

No interactions were observed $(\mathrm{p}>0.05)$ between the evaluated factors (Table 6). Lipid oxidation of the liver was reduced by supplementing lycopene in pig diets, and this response is

Table 6. Effects of dietary levels of lycopene for barrows and gilts (75 to $100 \mathrm{~kg}$ ) on the lipid oxidation by TBARS methodology (mg MDA/Eq. kg) and \% of inhibition of DPPH radicals of the liver

\begin{tabular}{|c|c|c|c|c|c|c|c|c|c|c|c|c|c|c|c|}
\hline \multirow{3}{*}{ Items } & \multirow{2}{*}{\multicolumn{5}{|c|}{$\begin{array}{c}\text { Barrows } \\
\text { Lycopene (mg/kg of diet) }\end{array}$}} & \multirow{2}{*}{\multicolumn{5}{|c|}{$\frac{\text { Gilts }}{\text { ne (mg/kg of diet) }}$}} & \multirow{3}{*}{ SEM } & \multicolumn{4}{|c|}{ p-value } \\
\hline & & & & & & & & & & & & \multirow{2}{*}{ Sexxlycopene } & \multirow{2}{*}{ Sex } & \multicolumn{2}{|c|}{ Lycopene } \\
\hline & 0 & 12.5 & 25.0 & 37.5 & 50.0 & 0 & 12.5 & 25.0 & 37.5 & 50.0 & & & & $\operatorname{Lin}^{1)}$ & Qua $^{2)}$ \\
\hline TBARS $^{3)}$ & 0.3302 & 0.3205 & 0.3094 & 0.2996 & 0.3027 & 0.3197 & 0.3069 & 0.2939 & 0.2894 & 0.2938 & 0.006 & 0.984 & 0.004 & 0.001 & 0.038 \\
\hline $\mathrm{DPPH}^{4)}$ & 5.8202 & 5.9244 & 6.2461 & 6.3839 & 6.3642 & 6.0372 & 6.2588 & 6.5662 & 6.5934 & 6.5325 & 0.111 & 0.958 & 0.003 & 0.001 & 0.068 \\
\hline
\end{tabular}

The eighty samples used.

TBARS, thiobarbituric acid reactive substances; MDA, malondialdehyde; DPPH, radical 2,2-diphenyl-1-picrylhydrazide; SEM, standard error of the mean; RSD, residual standard deviation.

1) Linear effect of lycopene levels.

2) Quadratic effect of lycopene levels.

3) $\hat{Y}=-0.0006 x+0.3211\left(R^{2}=0.84 ; R S D=0.0051\right) . \hat{Y}=0.00002 x^{2}-0.0014 x+0.3261\left(R^{2}=0.98\right)$.

4) $\hat{Y}=0.0115 x+5.98\left(R^{2}=0.84 ; R S D=0.1003\right)$; The independent variable " $x$ " represents the lycopene levels in the fitted equations. 
described by the equations $\hat{Y}=-0.0006 x+0.3211\left(R^{2}=0.84\right.$; $\mathrm{RSD}=0.005)$ and $\hat{\mathrm{Y}}=0.0000 \mathrm{x}^{2}-0.0014 \mathrm{x}+0.3261\left(\mathrm{R}^{2}=0.98\right)$, and the derivation of the quadratic equation provided a level of $34.47 \mathrm{mg}$ of lycopene $/ \mathrm{kg}$ of diet.

The capture of the DPPH radical by antioxidants in the liver was increased ( $p=0.001$ ) (Table 6), resulting in an increase in the antioxidant power exerted by lycopene in the liver due to the increase in dietary supplementation of lycopene $(\hat{Y}=$ $\left.0.0115 x+5.98 ; R^{2}=0.84 ; R S D=0.1003\right)$. The concentrations of TBARS and DPPH in the liver were affected by sex ( $\mathrm{p}=$ 0.001 ), in which the gilts showed the lower production of malonaldehyde and greater capture of the DPPH radical by antioxidants than barrows.

\section{DISCUSSION}

Daily lycopene intake, carcass traits, pork quality and relative organ weights

The inclusion of lycopene in the diet did not influence feed intake, because there was a linear increase in lycopene intake as the levels of lycopene in the diet were increased. In addition, the daily lycopene intake was influenced by sex with the barrows having a higher consumption of lycopene than gilts, this result can be explained by the fact that barrows are less efficient than gilts, requiring a higher feed intake. The carcass traits and relative organ weights were not affected by dietary lycopene levels (Table 2). However, sex showed differences for HCY, CCY, LMY, BT, and abdominal fat. These results may be related to the fact that sex directly affects the body composition of pigs by the action of sex hormones [16].

In this study, the evaluated dietary lycopene levels did not affect the color of the LL muscle, suggesting that lycopene can be added into the diet without affecting the instrumental color parameters of the LL muscle. The same response was observed by Chung et al [17], who evaluated the effect of lycopene on pigs supplemented with by-products of tomato processing and did not observe any effects on the color and $\mathrm{pH}$ of pork. However, sex affected the LL muscle color, as barrows presented higher intensities of red than did females, and similar results were observed in another study [18]. Evaluating the factors affecting LL colour [19] observed that the most important factors affecting $\mathrm{a}^{*}$ are the content of pigments (haematin) and the metmyoglobin fraction (MetMb), followed by the deoxymyoglobin fraction $(\mathrm{Mb})$ and the internal reflectance (FOP value), but the oxymyoglobin fraction $(\mathrm{MbO})$ did not affected $\mathrm{a}^{*}$ value. The intensity of the red $\left(\mathrm{a}^{*}\right)$ depends mainly on the ratio between the amount of oxidized MetMb and oxygenated $\mathrm{MbO} 2$, because MetMb is the less redish of the three myoglobin forms, contributing to a reduction of redness $\left(\mathrm{a}^{*}\right)[20]$.

The DL and CL did not differ between treatments, suggesting that lycopene supplementation did not result in high water losses of the LL muscle. However, the TL showed a reduction according to increasing levels of dietary lycopene, that is an important economic factor, since a high-water loss provides an unattractive appearance of the meat to the consumer. This reduction of muscle TL as the inclusion of lycopene in the diet increased can be explained by the antioxidants preserving the integrity of the muscle cell membrane, reducing the water loss.

Although the shear force was not affected by increasing lycopene levels in the diet (Table 3), a reducing trend was observed, which may be related to improving the meat tenderness, since antioxidants avoid the oxidation of sarcoplasmic proteins [21] as the main enzymes responsible for rigor mortis ( $\mu$-calpain and $m$-calpain) have a cysteine residue that can be oxidized. Avoiding the calpain oxidation contributes to a high proteolysis during maturation of the meat, making it soft. The shear force reported in this study shows an extreme softness range, including the maximum value (30.11 $\mathrm{N}$ ), corroborating the results found in the LL of antioxidantfed pigs [22].

\section{Total antioxidant activity by the DPPH radical and lipid oxidation by thiobarbituric acid reactive substances of the LL muscle}

Another interesting result of this study was the reduction of lipid oxidation in all of the evaluated storage periods: 0,24 , 48 , and 72 hours (Figure 1a) as dietary lycopene supplementation was increased. Lipid oxidation is a process related to the deterioration of fatty acids producing high values of TBARS, which are usually associated with unpleasant meat odor and taste [23] due to the development of a thiobarbituric acid reaction with saturated aldehydes (2-enals and 2-dienals), produced in the finishing phase of lipid oxidation. As in this study, that reaction shows a reduced concentration of malonaldehyde in the LL muscle. An et al [8] also observed that the inclusion of $20 \mathrm{mg}$ of lycopene/ $\mathrm{kg}$ of diet resulted in lower MDA concentrations in fresh pork belly meats of finishing pigs and observed significant values of lycopene in meat and no change in the fatty acid composition of fresh belly meat. In this way, it is suggested that enhanced oxidative stability of pork meat is due to the incorporation of lycopene, rather than lycopene-induced alteration of fatty acid composition or lipid metabolism.

The oxidation processes tend to increase over the storage days, impairing the shelf life of the meat. In addition, this study showed that lipid oxidation increased over the long storage days for all lycopene levels studied (Figure 1b), which was expected. According to Sindelar et al [24], the minimum lipid oxidation was 0.008 and $0.117 \mathrm{mg} \mathrm{MDA} / \mathrm{Eq} \mathrm{kg}$ for pork, and in this study, values above the minimum lipid oxidation were observed starting at $48 \mathrm{~h}$ of storage, only for the samples with the inclusion of $0,12.5$, and $25.0 \mathrm{mg}$ of lycopene. However, 
starting at $72 \mathrm{~h}$, the LL muscle at all lycopene levels showed values above the minimum suggested by Sindelar et al [24]. According to these results, lycopene was able to delay the oxidation during the studied time (72 hours of pork storage). However, evaluating tomato by-products in one raw pork emulsion, during refrigerated storage for 9 day, Joseph et al [25] observed a lower MDA values for treatments with tomato by-products than the control treatment during 9 days of storage. In the same way, there is extensive evidence indicating the protective role of antioxidants by retarding lipid oxidation and prolonging the lifespan of in natura pork meat [2].

This oxidation reaction by lycopene can be explained by the mode of action of the antioxidants, preventing lipid peroxidation due to the elimination of the initiating radicals, or acting as a bond catalyst, such as metal ions, to prevent the initiation of radical generation or by the peroxide decomposition. Thus, it cannot be reconverted into initiator radicals by performing chain breaks to avoid the continuous uptake of hydrogen by active radicals [7]. In the case of lycopene, the antioxidant action is based on its ability to extinguish singlet oxygen $\left({ }^{1} \mathrm{O}_{2}\right)$ and other oxygenated species, resulting in cellular protection against oxidative damage; that is, lycopene intercepts oxidative species before damage occurs. By physically extinguishing ${ }^{1} \mathrm{O}_{2}$ with lycopene, the deactivation occurs by transferring the excitation energy of ${ }^{1} \mathrm{O}_{2}$ to the lycopene molecule, and this causes the lycopene to reach the triplet state, and the energy of the excited lycopene is dispensed through vibrational interactions, recovering the state of the carotenoid [26] due to its conjugated polyene structure, which is responsible for this reaction, making the lycopene a potent antioxidant.

The efficiency of lycopene as an antioxidant can also be observed from the results of the DPPH radical scavenging test (Table 5), where all meat samples showed a greater capacity to eliminate the DPPH radical due to the increase in dietary lycopene. The antioxidant power of lycopene in the meat increased with its increasing levels in pig diets. No studies evaluating the action lycopene in pigs' diets, or tomato byproducts, on DPPH were reported until now. However, extract of tomato powder [27] displayed antioxidant activity in the DPPH radical-scavenging assay in cooked pork patties during storage at $10^{\circ} \mathrm{C} \pm 1^{\circ} \mathrm{C}$ in the dark. The $\mathrm{DPPH}$ radical elimination assay also revealed that the antioxidant power exerted by lycopene on meat was affected by the storage period (Table 5) because the inhibition of the DPPH radical was reduced over the 72 hours evaluated.

Among the methods used to control lipid oxidation, the use of antioxidants is the most effective, convenient and economical means. In addition to protecting products from deterioration, this additive can also be used for health promotion because of its ability to protect the body against oxidative damage [28]. This protection can be confirmed by the re- sults obtained in this study, such as dietary supplementation of lycopene, in addition to reducing lipid oxidation and increasing the antioxidant power in the meat, with a similar effect on the liver.

\section{Total antioxidant activity by the DPPH radical and lipid oxidation by thiobarbituric acid in the liver} Lipid oxidation of the liver was reduced by the supplementation of lycopene in the pig diet, in which supplementation of $34.47 \mathrm{mg}$ of lycopene $/ \mathrm{kg}$ of diet resulted in a lower oxidation of the hepatic tissue (Table 6), showing that lycopene can be a potent antioxidant in eliminating free radicals in vivo. Due to its polyene structure, lycopene provides an electron-rich system and is an eligible target for electrophilic reagents. Thus, lycopene shows high reactivity against free radicals and oxygen [26]. Similar results were observed by Sun et al [6], reporting that dietary supplementation of lycopene reduced the malonaldehyde content in the liver.

The capture of the DPPH radical increased linearly in the liver of the pigs (Table 6) with the increasing inclusion of lycopene in the diet, resulting in an increase in the total antioxidant power of 7.08\%. Similar values were found by Joseph et al [25], showing that pig liver DPPH was $9.90 \%$. In addition, some studies suggest a dose-dependent effect on radical removal of DPPH by antioxidants [29]. Lycopene of diet-origin has the liver as a main destination [6], probably this is the explanation of the lower concentration of MDA and greater capture of the radical DPPH in the liver of finishing pigs, since lycopene acts by intercepting oxidant species before tissue damage occurs [26]. The TBARS and DPPH in the liver were affected by sex, and gilts presented a lower lipid oxidation and higher capture of the DPPH by antioxidants than barrows. Females appear to be less susceptible to oxidative damage due to the higher genetic expression of antioxidants and to the lower oxidative damage of mitochondria [30]. In addition, there is evidence of the strong antioxidant properties of estrogen and differences in nicotinamide adenine dinucleotide phosphateoxidase activity [31]. Liu et al [32] reported higher levels of MDA in male rats, and this difference was attributed to sex because of the effects of sex hormones.

This effectiveness of lycopene in protecting LL meat and liver of pigs against oxidation (Tables 4,5 , and 6 ) is of great importance because lipid oxidation is a process in which unsaturated fatty acids react with oxygen and free radicals, through a chain reaction mechanism giving rise to the formation of lipid hydroperoxides and other by-products, such as aldehydes that are responsible for rancidity and spoilage of food [33]. Pork and its products are highly sensitive to lipid oxidation [3], which can mainly affect meat quality attributes such as color, taste, texture and nutritional values [2], which are determining factors for the consumer. 


\section{CONCLUSION}

The inclusion of lycopene in the diet of barrows and gilts reduced the liquid loss in thawing and was effective in the protection against oxidation of LL muscle and liver until 72 hours of storage, and the best results were obtained when $50.0 \mathrm{mg}$ of lycopene $/ \mathrm{kg}$ of diet was supplemented.

\section{CONFLICT OF INTEREST}

We certify that there is no conflict of interest with any financial organization regarding the material discussed in the manuscript.

\section{ACKNOWLEDGMENTS}

The Conselho Nacional de Desenvolvimento Científico e Tecnológico $(\mathrm{CNPq})$ by research funding and the Coordenação de Aperfeiçoamento de Pessoal de Nível Superior (CAPES) by the granting of the scholarship.

\section{REFERENCES}

1. Papuc C, Gheorghe VG, Corina NP, Nicorescu V. Mechanisms of oxidative processes in meat and toxicity induced by postprandial degradation products: a review. Food Sci Food Saf 2017;16:96-123. https://doi.org/10.1111/1541-4337.12241

2. Karakaya M, Bayrak E, Ulusoy K. Use of natural antioxidants in meat and meat products [abstract]. J. Food Sci Eng 2011;1(Issue 1):10.

3. Yi AG, Haug BA, Nyquist BNF, Egelandsdal B. Hydroperoxide formation in different lean meats. Food Chem 2013;141:265665. https://doi.org/10.1016/j.foodchem.2013.05.041

4. Moroney NC, O'Grady MN, O'Doherty JV, Kerry JP. Addition of seaweed (Laminaria digitata) extracts containing laminarin and fucoidan to porcine diets: influence on the quality and shelf-life of fresh pork. Meat Sci 2012;92:423-9. https://doi.org/10.1016/j.meatsci.2012.05.005

5. Rajauria G, Jaiswal AK, Abu-ghannam N, Gupta S. Antimicrobial, antioxidant and free radical-scavenging capacity of brown seaweed Himanthalia elongata from western coast of ireland. J Food Biochem 2013;37:322-35. https://doi.org/ 10.1111/j.1745-4514.2012.00663.x

6. Sun B, Chen C, Wang W, et al. Effects of Lycopene supplementation in both maternal and offspring diets on growth performance, antioxidant capacity and biochemical parameters in chicks. J Anim Physiol Anim Nutr 2015;99:42-9. https:// doi.org/10.1111/jpn.12196

7. Dorman HJD, Peltoketo A, Hiltunen R, Tikkanen MJ. Characterisation of the antioxidant properties of de-odourised aqueous extracts from selected Lamiaceae herbs. Food Chem 2003;83: 255-62. https://doi.org/10.1016/S0308-8146(03)00088-8
8. An BK, Kim DH, Joo WD, Kang CW, Lee KW. Effects of lycopene and tomato paste on oxidative stability and fatty acid composition of fresh belly meat in finishing pigs. Ital J Anim Sci 2019;18:630-5. https://doi.org/10.1080/1828051X. 2018.1549963

9. Chung SH, Son AR, Le SA, Kim BG. Effects of dietary tomato processing byproducts on pork nutrient composition and loin quality of pig. Asian J Anim Vet Adv 2014;9:775-81. http:// dx.doi.org/10.3923/ajava.2014.775.781

10.Correia CS, Alfaia CM, Madeira MS, et al. Dietary inclusion of tomato pomace improves meat oxidative stability of young pigs. J Anim Physiol Anim Nutr 2017;101:1215-26. https:// doi.org/10.1111/jpn.12642

11. Bridi AM, Silva CA. Pork meat evaluation. Londrina, Brazil: 1th ed. Midigraft; 2009.

12. Boccard R, Buchter L, Casteels E, et al. Procedures for measuring meat quality characteristics in beef production experiments. Report of a working group in the Commission of the European Communities' (CEC) beef production research programme. Livest Prod Sci 1981;8:385-97. https://doi.org/10. 1016/0301-6226(81)90061-0

13. Juncher D, Rønn B, Mortensen E, et al. Effect of pre-slaughter physiological conditions on the oxidative stability of colour and lipid during chill storage of pork. Meat Sci 2001;58:34757. https://doi.org/10.1016/S0309-1740(00)00156-X

14. Brand-Williams W, Cuvelier ME, Berset C. Use of a free radical method to evaluate antioxidant activity. LWT - Food Sci Technol 1995;28:25-30. https://doi.org/10.1016/S0023-6438 (95)80008-5

15.Li W, Shan F, Sun S, Corke H, Beta T. Free radical scavenging properties and phenolic content of Chinese black-grained wheat. J Agric Food Chem 2005;53:8533-6. https://doi.org/ 10.1021/jf051634y

16.Patience JF, Rossoni-Serão MC, Gutiérrez NA. A review of feed efficiency in swine: biology and application. J Anim Sci Biotechnol 2015;6:33. https://doi.org/10.1186/s40104-0150031-2

17. Chung SH, Son AR, Le SA, Kim BG. Effects of dietary tomato processing byproducts on pork nutrient composition and loin quality of pigs. Asian J Anim Vet Adv 2014;9:775-81. http://dx.doi.org/10.3923/ajava.2014.775.781

18. Latorre MA, Lazaro R, Gracia MI, Nieto M, Mateos GG. Effect of sex and terminal sire genotype on performance, carcass characteristics, and meat quality of pigs slaughtered at 117 kg body weight. Meat Sci 2003;65:1369-77. https://doi.org/ 10.1016/S0309-1740(03)00059-7

19. Lindahl G, Lundström K, Tornberg E. Contribution of pigment content, myoglobin forms and internal reflectance to the colour of pork loin and ham from pure breed pigs. Meat Sci 2001;59: 141-51. https://doi.org/10.1016/S0309-1740(01)00064-X

20. Karamucki T, Jakubowska M, Rybarczyk A, Gardzielewska J. The influence of myoglobin on the colour of minced pork loin. 
Meat Sci 2013;94:234-8. https://doi.org/10.1016/j.meatsci. 2013.01.014

21. Rowe LJ, Maddock KR, Lonergan SM, Huff-Lonergan E. Oxidative environments decrease tenderization of beef steaks through inactivation of $\mu$-calpain. J Anim Sci 2004;82:325466. https://doi.org/10.2527/2004.82113254x

22. Simitzis PE, Symeon GK, Charismiadou MA, Bizelis JA, Deligeorgis SG. The effects of dietary oregano oil supplementation on pig meat characteristics. Meat Sci 2010;84:670-6. https:// doi.org/10.1016/j.meatsci.2009.11.001 https://doi.org/10.1016/ j.meatsci.2009.11.001

23. American Meat Science Association (AMSA). American Meat Science Association's meat colour measurement guidelines [internet]. Raosoft Inc.; c2012 [cited 2016 nov 5]. Available from: http://www.meatscience.org/publications-resources/ printedpublications/amsa-meat-color-measurement-guidelines

24. Sindelar JJ, Prochaska F, Britt J, Smith GL, Osburn WN. Strategies to eliminate atypical aromas and flavors in sow loins-part II: consumer acceptance of loins marinated with sodium tripolyphosphate and sodium bicarbonate. Meat Sci 2003;65: 1223-30. https://doi.org/10.1016/S0309-1740(03)00028-7

25. Joseph S, Chatli MK, Biswas AK, Sahoo J. Oxidative stability of pork emulsion containing tomato products and pink guava pulp during refrigerated aerobic storage. J Food Sci Technol 2014;51:3208-16. https://doi.org/10.1007/s13197-012-0820-y

26. Krinsky NI. The antioxidant and biological properties of the carotenoids. Ann NY Acad Sci 1998;854:443-7. https://doi. org/10.1111/j.1749-6632.1998.tb09923.x
27.Kim IS, Jin SK, Yang MR, et al. Efficacy of tomato powder as antioxidant in cooked pork patties. Asian-Australas J Anim Sci 2013;26:1339-46. https://doi.org/10.5713/ajas.2013.13079

28. Pajk T, Rezar V, Levart A, Salobir J. Efficiency of apples, strawberries, and tomatoes for reduction of oxidative stress in pigs as a model for humans. Nutrition 2006;22:376-84. https://doi. org/10.1016/j.nut.2005.08.010

29. Balakrishnan B, Prasad B, Rai AK, et al. In vitro antioxidant and antibacterial properties of hydroLysed proteins of delimed tannery fleshings: comparison of acid hydrolysis and fermentation methods. Biodegradation 2011;22:287-95. https://doi. org/10.1007/s10532-010-9398-0

30. Borras C, Sastre J, Garcia-Sala D, Lloret A, Pallardo FV, Vina J. Mitochondria from females exhibit higher antioxidant gene expression and lower oxidative damage than males. Free Radic Biol Med 2003;34:546-52. https://doi.org/10.1016/S0891-5849 (02)01356-4

31.Tudus PM. Estrogen and gender effects on muscle damage, inflammation, and oxidative stress. Can J Appl Physiol 2000; 25:274-87. https://doi.org/10.1139/h00-022

32. Liu Y, Zhang H, Zhang L. Evaluation of sex specificity on oxidative stress induced in lungs of mice irradiated by $12 \mathrm{C} 6+$ ions. Nucl Sci Tech 2008;19:17-21. https://doi.org/10.1016/S10018042(08)60016-0

33. Shahidi F, Zhong Y. Lipid oxidation and improving the oxidative stability. Chem Soc Rev 2010;39:4067-79. https://doi. org/10.1039/B922183M 